\title{
Factors Affecting Family Planning Literacy: Perspectives of Women of Childbearing Age in Rural Lake Zone, Tanzania
}

\author{
Mohamed Kassim ( mohdie2@yahoo.com) \\ University of Dar es Salaam \\ Faraja Ndumbaro \\ University of Dar es Salaam
}

\section{Research Article}

Keywords: Family planning, family planning literacy, health literacy, women of childbearing age, rural Lake Zone, Tanzania

Posted Date: November 24th, 2020

DOI: https://doi.org/10.21203/rs.3.rs-107991/v1

License: (c) (i) This work is licensed under a Creative Commons Attribution 4.0 International License. Read Full License 


\section{Abstract}

Background Low uptake of various recommended modern family planning methods is associated with inadequate family planning literacy among potential beneficiaries of the methods. As such, understanding the factors affecting family planning literacy is key to addressing this problem. This study, therefore, explored factors affecting family planning literacy of women of childbearing age in the rural Lake Zone of Tanzania.

Methods The study utilized an exploratory descriptive qualitative research approach using focus group discussions to collect data. A total of eight focus group discussion sessions were held to solicit information from women of childbearing age involved in the study. Thematic analysis was used to analyze the data collected from the respondents.

Results Inadequate family planning literacy has been found among women of childbearing age in the studied communities. Sociodemographic factors such as education level, religious affiliation, and family income have been found to negatively affect the family planning literacy of the women in this study. Other factors such as fertility preference, negative perceptions about family planning, preference of unproven traditional family planning methods, limited access to reliable sources of information, household responsibilities, and poor male partner support were also found to affect women's family planning literacy.

Conclusion Inadequate family planning literacy among women of childbearing age reduces the women's chances of obtaining relevant family planning information as well as limiting their abilities to process and understand the information so as to be able to make informed decisions about their reproductive health. Therefore, addressing factors affecting family planning literacy of the women is imperative in increasing their overall uptake of various recommended modern family planning methods.

\section{Background}

Family planning is widely recognized as essential in helping women and their male partners to decide freely, and for themselves; whether or when to have children and how many to have $(1,2)$. This helps them to improve both maternal and child health, reduce the prevalence of unwanted pregnancies and unsafe abortions, prevent sexually transmitted infections, and improve the economic well-being of their families (3-5). Family planning is also important in promoting women's sense of autonomy and their ability to make decisions about their health and of those in their care (6). As such, the United Nations (UN) has made it a priority to increase and sustain the utilization of family planning because it considers it crucial in the attainment of sustainable development goals. To do so, emphasis is put on universal access to a full range of safe and reliable family planning methods to help couples realize their rights to freely and responsibly decide the number and spacing of their children $(2,7)$.

According to the World Health Organization (WHO) (8), around 57\% of women of childbearing age are using family planning globally. However, while evidence shows that there is a global increase in the use of family planning, especially in Asia (61.8\%) and Latin America (66.7\%), the situation is different in sub-Saharan Africa, Tanzania included, where the usage of such services continues to be low (9). In fact, it is estimated that only $28.5 \%$ of women of childbearing age in sub-Saharan Africa are using family planning (8) and that more than 200 million women wishing to prevent unwanted pregnancies are not using the services (10).

Tanzania has witnessed a notable increase, from $7 \%$ in 1991 to $32 \%$ in 2015 , in the utilization of modern family planning methods among women (11-13). However, despite such growth, it is estimated that about $22 \%$ of women of childbearing age in the country who would like to delay or stop childbearing are not using any form of family planning (14). Furthermore, there is a large variation in terms of access to and use of family planning methods geographically in the country, with some regions reported to have a considerably lower than average usage (15).

Persistently low uptake of family planning in Tanzania has been more reported in the Lake zone (15\%) than in any other part of the country $(11,12,16)$. This zone is also reported to have a high $(33 \%)$ unmet need for family planning compared to the rest of the country as many women who wish to use such services do not manage to do so $(11,16)$. As a result, the women in this zone are at risk of experiencing various reproductive health and socioeconomic problems. Evidence shows, for instance, that low usage of family planning has contributed to high fertility rates (17) which is considered as one of the risk factors for maternal morbidity and mortality (18). As a result, the women and their families are likely to be faced with financial burdens resulting from health services costs $(17,19)$.

Low usage of family planning services in most sub-Saharan countries, Tanzania included, is associated with, among other factors, inadequacy health literacy among women of childbearing age $(6,20-22)$. Health literacy, as defined in various existing studies $(23,24)$, refers to the degree to which people have the capacity to obtain, process, and understand basic health information and services needed to make appropriate health decisions. This concept is widely recognized as one of the most significant social determinants of health (25-27) and is, thus, essential in changing people's attitudes towards acceptance and uptake of various recommended family planning methods. 
There is evidence in the literature that people with inadequate health literacy tend to be less knowledgeable of their health conditions, less likely to use preventive health care services, and more likely to be hospitalized (28). Such individuals can also be easily misguided by incorrect sources of health information (29). In the context of family planning, inadequate family planning literacy is reported to contribute to poor acceptance, wrong use, and low uptake of various recommended modern family planning methods (20-22,30).

Inadequate health literacy, as reported in previous studies (31-33), is more prevalent among people in rural areas than those in urban areas. This appears to explain the reported low uptake of recommended modern family planning methods by most people in rural areas (17,22,3436). In fact, research shows that unlike their urban counterparts, women residing in rural areas are more likely to be affected by all types of unmet needs for family planning services $(22,35)$. Women residing in these areas are reported to be more likely to identify inadequate health literacy as the main barrier to their uptake of various recommended modern family planning methods (22).

In view of the afore-described background, it is, therefore, imperative to explore factors affecting the family planning literacy of women residing in rural areas. Understanding these factors is crucial in addressing the problem of low uptake of modern family planning methods among women of childbearing age in these areas. In this regard, the study, therefore, explored the perspectives of women of childbearing age residing in rural Tanzania on factors affecting their family planning literacy.

\section{Methods}

The study employed an exploratory descriptive qualitative research approach to explore factors affecting family planning literacy of women of childbearing age in rural Lake Zone of Tanzania. As noted earlier, this zone is reported to have a comparatively lower (15\%) uptake of family planning than the rest of the country $(11,12,16)$. Four regions from the zone namely Shinyanga, Simiyu, Mara, and Kagera were purposively selected to take part in the study. Out of these regions, four districts, one from each region (Shinyanga Rural in Shinyanga, Bariadi in Simiyu, Musoma in Mara, and Bukoba in Kagera), were purposely selected to be representatives of the rural areas of the Lake Zone.

The study involved women of childbearing age between 15 to 49 years residing in rural areas of the four selected districts. Purposive sampling was used to select respondents for inclusion in the study. The inclusion criteria were being a woman aged between 15 to 49 years; and living in rural areas. Local community health workers from the respective villages contributed to the identification of potential households where individuals meeting the set inclusion criteria could be found.

Data from the respondents were mainly collected using focus group discussions (FGDs) based on a guide initially developed in English before being translated into Kiswahili for use. The FGD guide consisted of open-ended questions which were used to solicit information on participants' perspectives concerning factors affecting their family planning literacy. In all, a total of 8 FGDs involving a total of 72 participants were held in the selected villages of the four districts involved in the study. Each FGD session lasted between 60 and 90 minutes. To ease participants' attendance, the FGDs were held at places very accessible to them while also ensuring their comfortability.

All the discussions were audio-recorded. In addition to the audio recordings, fieldnotes were taken by the researchers. The recordings were transcribed verbatim into Kiswahili, later translated into English, and reviewed by the researchers. After being reviewed, the transcripts were imported, coded, and analyzed thematically using NVivo software (QSR version 12). Different themes from the transcripts were organized where similar ones were grouped together.

\section{Ethical considerations}

The study received ethical approval from the Tanzania National Institute for Medical Research (NIMR) Institutional Review Board (IRB). Permission to conduct the study was also sought from the local authorities in the four selected regions. The study also obtained informed verbal consent from discussion participants before they participated in the study. Consent for minor, that is those aged below 18 years, was obtained from their parents/guardians in order for them to participate in the study. All the study participants were assured that their participation would be kept anonymous throughout the study. All the methods used in this study are in accordance with the relevant guidelines and regulations.

\section{Results}

A total of seventy-two (72) women of childbearing age between 15 to 49 years from rural areas of the four selected regions participated in the focus group discussions. From the discussions, several factors were found to affect family planning literacy of the study participants. These factors have been grouped into seven (7) themes as described in sections that follow:

\section{Socio-demographic factors}


Three socio-demographic factors namely education, household economic status, and religious beliefs were found to affect the family planning literacy of women of childbearing age in this study.

\section{Education}

There were mixed feelings from respondents about how education affects their family planning literacy. On one hand, many women in FGDs associated their inadequate family planning literacy with low levels of education among them and their male partners. They argued that because of their low levels of education, it is difficult for them to comprehend various family planning information coming from different sources. As such, many of them are not able to utilize the available family planning services. One woman stated that:

... for instance, sometimes we are told to use a calendar as one of the family planning methods. However, this method might be good for those who have adequate levels of literacy as it might be easier for them to follow their calendars. The problem is that it is difficult, especially for us who have not gone to school, to apply such a method as most of us do not know how to follow such a calendar(FGD, females, rural - Mara).

On the other hand, other respondents, particularly those who have at least attained a primary level of education and thus know how to read and write, argued that education has enabled them to know various family planning methods, and thus it is easy for them to use such services. The respondents pointed out that because they can read, it is easy for them to follow family planning messages from different sources. As such, these women developed more interest in finding more information about various family planning methods and thus being able to decide on whether to use the methods or not. In relation to this, one study participant pointed out that:

Many people who are educated and more informed are now using family planning to control the number of children they want to have. As such, you may find them more interested in finding information about different forms of family planning (FGD, females, rural - Shinyanga).

Understandably, the FGDs also showed that apart from helping study participants to know various family planning methods, education also helped them to realize the importance of family planning. Having that knowledge makes it is easier for women targeted by the study to make decisions on the appropriate family planning methods to use.

\section{Household economic status}

The economic status of a family was also seen as one of the determinants of women's family planning literacy. Firstly, this was described based on the economic hardship a family faces when there are many children. Most respondents described how difficult it is for them to take care of many children in their families due to economic hardships. They explained that such hardships compel them to start thinking about using family planning so as to be able to reduce the number of unwanted pregnancies and thus having manageable family sizes. As such, many of them started gathering information about family planning from different sources. One woman lamented that:

Our income is very small, but we have a lot of children to take care of. So, as a family, I and my husband thought that now is the right time for us to start thinking about family planning. That is why we have started gathering information about it (FGD, females, rural - Kagera).

Respondents also linked household economic status to their families' ability to possess means of communication such as radio and television through which they could be able to get family planning-related information. The women argued that because of their poor economic statuses, many of them cannot afford to own such sources of information. As a result, it is not easy for them to follow family planning information disseminated through these sources; something that also affects their family planning literacy evident in the following statement made by one participant:

We know that we can also get such information from radio or television. Unfortunately, I do not have any of them... I do not have a radio or television. I cannot just go to other people's houses to listen to their radio or watch television just for family planning information. It is a disgrace (FGD, females, rural - Simiyu).

\section{Religious beliefs}

Religious beliefs were also found to affect women's family planning literacy. According to some study participants, some religions discourage their believers to use any form of family planning as doing so is like killing the sperms and eggs and thus preventing birth. This, according to them, is against God's will that people should give birth and replenish the earth. Using family planning is, therefore, considered as interfering with God's plan. One Muslim woman recounted that:

Our religion does not allow us to use any form of family planning. Using it is like killing your eggs and your unborn child. That is why you will never hear any Imam or Sheikh in the mosque preaching to his followers about using family planning. I think that is why many people are not even interested in finding information about it (FGD, females, rural - Kagera). 
Another woman pointed out that:

Our religious leaders discourage us from using family planning. They tell us that our religion prohibits the usage of such services. They want us to continue giving birth because that is what we have been created for... giving birth (FGD, females, rural -Mara).

This situation, as recounted by the women, discourages them and their male partners from seeking any family planning-related information and, as a result, their family planning literacy continues to be low. As such, some women and their partners do not use any kind of recommended modern family planning methods.

\section{Fertility preference}

There were also contrasting views among women involved in FGDs about the role of fertility preference in their family planning literacy. Some FGD participants mentioned that there is an association between a desire to have large family and inadequate family planning literacy. Such desire is linked to attitudes and preferences of some family members, particularly male partners, and the community to have many children in families. FGD participants reported that such an attitude and preference influence women and their male partners into ignoring various family planning messages delivered to them through different channels. Explaining this, one woman stated that:

It is not that I don't want to use family planning. The problem is that my husband wants to have many children. He says that his father's family had only a few children and most of them were females. So as a male child in the family, he bears the responsibility of developing his clan. As such, he doesn't want to hear anything about family planning (FGD, females, rural - Shinyanga).

In contrast, other women in the FGDs were of the view that currently, many couples prefer to have fewer children as compared to the past. As noted earlier, the women attributed these changes to their low levels of income which motivated them to start thinking about using family planning. They thought that having many children would impair their economies and thus making them fail to take care of their families. Contributing this discussion, one participant explained that:

To be honest, life is very difficult. How are you going to raise all your children in these difficult times? How are you going to provide for them? You know, it's time now we stop that kind of thinking. Having many children in the family is a burden. Actually, I and my husband have started thinking about using family planning. We just want to have a small manageable family (FGD, females, rural - Kagera).

\section{Negative perceptions and misinformation about family planning}

Findings from this study reveal that there are still a lot of negative perceptions and misinformation about family planning among many women in rural areas. This, as a result, limits women's efforts to seek accurate information about family planning and thus affecting their family planning literacy. A widely held perception among women is that many modern family planning methods have negative side effects or are harmful to the body of the user. In one FGD, one participant remarked that:

I think there is confusion when it comes to the use of family planning. It might be true that we have never used any family planning method before, but what we hear from other people, especially those who have tried to use, is that these methods have many side effects on those who are using them (FGD, females, rural - Shinyanga).

The commonly mentioned side effects of family planning include continuous bleeding, irregular menses, cancer, loss of sexual desire, swollen stomachs, weight gain or loss, having a disabled child, and being infertile. There was a consensus among study participants that, to a large extent, these perceptions affect their understanding of various modern family planning methods, and as such have contributed to low usage of the same.

The following quotes also illustrate the women's concern about the side effects of modern family planning methods:

Another side effect that most people are talking about is the danger of getting cervical cancer for women. They say that once you start using the pills, your belly will start to swell... that is when you know that you have problems. This is why many people are discouraging their use (FGD, females, rural -Mara).

For instance, at our school, we have a special program for disabled children. Now if you try to trace the source of the disabilities for many children, you will find that they are disabled because of their mothers' use of syringes (contraceptives) when they were pregnant. So, the syringes affected the fetus in the womb and that is why the children were born disabled (FGD, females, rural - Simiyu).

These misconceptions create fear among women such that their utilization of the various family planning methods continues to be low. However, comparatively, many of these misconceptions were more observed in Mara region than in the other three studied regions.

\section{Use of unproven traditional methods of family planning}


Consistent use of unproven traditional methods of family planning, especially local concoctions and magic was also reported to affect the family planning literacy of some women of childbearing age in some of the studied communities. Again, this problem was reported more in Mara region than in the other three studied regions. Some women in this region reported preferring using concoctions from traditional healers than the recommended modern family planning methods. The use of such concoctions is considered as an alternative free of side effects believed to be common among many modern family planning methods as narrated by one participant in one of the FGDs as follows:

Someone may tell you that she took a pill and then her belly started to swell...others may say they have bled the whole month after using some forms of modern family planning, or they were very thin but all of a sudden after using the pills started gaining weight. So, these things are real. You may ask yourself why expose yourself to all these problems while there are other safer options from traditional healers (FGD, females, rural - Mara).

Other women also pointed out that:

I normally go to a traditional healer for her concoctions...I would rather use the concoctions than those medicines from the health center. At least the concoctions won't make me infertile like the medicines from the health center (FGD, females, rural - Mara).

Why should I kill myself with the pills from the hospital? We already know that they are not safe. If you are using herbals your belly will not swell, you will not gain weight, and there will be no over bleeding. Your body will just be the same (FGD, females, rural - Simiyu).

However, overall, findings from FGDs indicate that the use of concoctions and other unproven traditional family planning methods have led to some women who believe in those methods, becoming less interested in seeking information about modern family planning methods and in using such methods as well. Nonetheless, as noted above, the women's use of these unproven traditional family planning methods can be attributed to negative perceptions and fear of potential side effects of various modern family planning methods as described by the women themselves.

\section{Limited access to reliable sources of family planning information}

Inability to access family planning-related information from reliable sources was also mentioned by some respondents as one of the factors that affect their family planning literacy. This problem was attributed to, among other things, shortage of health facilities and unavailability of professional health providers in some rural areas. This is especially true for all women who stayed far from health care facilities. As such, these women are compelled to use informal sources of information to meet their various health information needs, including family planning ones. When probed on where they first go when they have any query regarding the use of family planning or any other health-related issue, some respondents pointed out that they usually consult their immediate relatives or drug sellers in drugstores for such information. One woman remarked that:

Sometimes it is difficult to get information about family planning, especially for us who stay far from the health center. So, if I have not gone to the health center but still need to know something about my health or any family planning issue, I will ask my mother about it. If she is not around, I will just go to the drugstore and ask the seller about it. (FGD, females, rural - Bariadi).

Generally, findings from all FGDs indicate that the absence of health centers in some of the rural areas has led to many women in these areas turning to drugstore attendants for health information. However, the problem with these sources, as narrated by some women, is that they do not always provide relevant family planning information. This can be attributed to the fact that some of them are not trained and thus not qualified to not only sell drugs but also in providing health information.

\section{Household responsibilities}

Study participants also mentioned household responsibilities as one of the factors that affect their family planning literacy. Most women in the discussions agreed that their engagement in various household activities denied them enough time to effectively engage in seeking information about family planning. Even though the women admitted that sometimes such information is disseminated through various mass media sources such as radio and television, they pointed out that due to their tight schedules, it is sometimes difficult for them to get the information provided by these sources. Explaining this, one woman stated that:

Living in rural areas has some challenges. As women, we are required to engage in every activity in our households...from taking care of children in the house to working in our family farms. You hardly get time to listen to the radio, let alone go to the clinic for family planning services (FGD, females, rural - Mara).

When asked about accessing family planning information through mobile phones (which could otherwise help them access such information at their convenience), most women reported not being aware of such service despite having access to mobile phones. Furthermore, the few that said they were aware of such services mentioned that they had either not subscribed to such services or subscribed but ignore various family 
planning messages sent to their mobile phones. Again, household chores were cited by the women as an obstacle to accessing such information. For instance, one woman remarked that:

I have subscribed to that service. But as you know, sometimes I might be too busy to check messages when I hear notifications on my mobile phone, I just ignore it. I might promise myself that I will read the message later but, unfortunately, the day may end without doing so (FGD, females, rural - Simiyu).

\section{Men's involvement in and support for family planning matters}

Almost all the women that participated in this study acknowledged the importance of their partners' involvement in family planning and how that is likely to enhance their family planning literacy in particular. The women recounted that their partners' involvement in family planning is important because it helps them, as couples, to make decisions together on whether to use various recommended family planning methods or not. The women also mentioned that their partners are likely to adhere to various family planning instructions and information given by health service providers if they are involved in family planning matters from the very beginning. Explaining the importance of their partners' involvement in family planning, one study participant argued that:

If your partner is also involved in family planning matters, let's say, you are both provided with family planning information, it will be easier for him to adhere to requirements because he is also informed. In fact, you rest assured that once you forget anything, he will be the one to remind you (FGD, females, rural - Shinyanga).

Another woman stated that:

Yes, he may allow me to go to the clinic for family planning services, but the problem here is that I might not be able to tell him exactly what I have been taught at the clinic. If we go together, he will also have the same opportunity as mine, to listen to health service providers about family planning. This helps us couples to make decisions together regarding whether to use a certain family planning method or not. Otherwise, if he refuses to attend, he is also discouraging you from attending (FGD, females, rural - Mara).

Based on these narrations, it is safe to say that women whose male partners are supportive of solutions on matters to do with their reproductive health are more likely to have adequate family planning literacy than those with unsupportive partners. However, only a few study participants reported receiving such support from their male partners. As it would be expected, these women admitted that they were able to discuss various family planning matters with their male partners. For instance, one participant was quoted saying that:

He is very supportive. We usually talk about it. I remember when I was pregnant and even after delivery; he was accompanying me to the clinic. He, for instance, helped me to subscribe to M4RH (Mobile for Reproductive Health) services through my mobile phone so that I can receive family planning messages (FGD, females, rural - Shinyanga).

In contrast, most women in the study mentioned poor involvement of their male partners in family planning matters as one of the major factors affecting their family planning literacy. Most of them revealed that their male partners are not supportive of family planning. One participant in the discussion lamented that:

He kept on yelling at me..." so you want me to carry your handbag and go with you to the clinic? Am I the one who want to use family planning? Didn't you hear that such things have many side effects? Do you want also to get such problems?" That is what he was telling me... At such a point, I didn't have anything to say. I just sat down and cried. I was so disappointed (FGD, females, rural - Kagera).

Most women associated their partners' poor support for family planning-related matters with their fear of potential side effects of modern family planning methods, preference to have many children, and low levels of education. As such, the males discourage their partners from using family planning methods. Eventually, this discourages the women from seeking family planning-related information such that when the information is sought, it is done without the knowledge of their male partners.

\section{Discussion}

In this study, a qualitative approach has been used to explore perspectives of women of childbearing age on factors affecting their family planning literacy. Evidence from numerous studies $(30,37,38)$ shows that adequate family planning literacy is one of the most important determinants of family planning uptake among women of childbearing age. This study's findings suggest that most women of childbearing age in the studied communities have inadequate family planning literacy. This state is a result of a multitude of factors. The findings reveal a significant effect of socioeconomic inequalities on the study participants' family planning literacy. This is clear in the extent of unmet family planning information needs among women with no education and those with poor economic status compared to those with at least primary level of education and those with a better economic status. In fact, the study shows that while a majority of women who had no education were 
not able to follow and comprehend various family planning information, those with poor economic status were not able to access information disseminated through mass media sources such as radio and television. In this study, possession of these media sources has been found to be directly linked to one's economic status. Evidence from other previous studies $(6,39)$ also indicates an association between education and wealth with levels of family planning literacy of women in rural areas. However, it is encouraging to note in this study that poor economic statuses of many households in the studied communities has influenced some women in these households to start seeking family planning information. This clearly boosts family planning literacy which is likely to translate into uptake of various recommended family planning methods.

Consistent with findings from other studies $(17,40)$, this study has found that religious beliefs negatively affect family planning literacy of women of childbearing age. Several women that participated in this study saw usage of family planning as going against God's will for people to give birth and replenish the world. The women cited their religious leaders' discouragement of the use of family planning as their obstacle in seeking family planning-related information. This, however, might be due to varied interpretations of religious texts concerning family planning by some religious leaders as noted in other prior studies (40). While some religious leaders encourage the use of family planning, others do not. This situation impairs the family planning literacy of the women and puts them in a dilemma as to whether they should use family planning or not. This finding illustrates the influence that religious leaders have on their followers when it comes to matters related to family planning.

Despite various efforts made to provide communities and women, in particular, with family planning-related information (41), this study has found that there are still unmet needs for this important information in most of the studied communities. The findings demonstrate that there are still many misconceptions about family planning that affect women's understanding of various modern family planning methods. Many women and their partners are still associating modern family planning methods with various potential side-effects such as cancer, over bleeding, infertility, irregular menses, having disabled children, and swollen stomachs. Such misconceptions discourage women from using different forms of modern family planning. These findings, however, are not peculiar to this study as numerous past studies have also reported the same $(3,17,30,42)$.

The study's findings also show that some women in the studied communities are still using unproven traditional methods of family planning. As a result, these women do not make efforts to seek information about modern family planning methods. Although the women attributed their preference of traditional family planning methods to fear of potential side effects of modern methods, consistent use of unproven traditional methods puts them more at risk than using the later. Nevertheless, it was interesting to note a majority of study participants disapproving the usage of the traditional family planning methods, citing the risks the methods might have on their reproductive health. However, although only a minority of study participants confirmed the use of unproven traditional family planning methods, this finding cannot be ignored since these women live in the same communities with other women. As such, their beliefs are likely to defuse to other women and negatively influence their communities' family planning literacy.

The shortage of primary health care facilities and limited skilled personnel in some rural areas was also reported to affect the family planning literacy of women of childbearing age in this study. Because of such shortage, women in these areas reported relying on their immediate family members and drugstore attendants available in their villages as their sources of family planning information. Unlike the findings in the present study, previous studies $(6,20)$ have reported women's reliance on health workers, television, and radio for family planning information. Reliance on informal sources of health information, as found in this study, puts women at risk of receiving irrelevant family planning information which may contribute to their low uptake of various modern family planning methods.

As noted in this study, a significant number of respondents agreed that their engagement in various household activities also limits their family planning literacy. Such engagements deny them sufficient time to effectively engage in seeking family planning information. Although the women admitted that they could also get such information from mass media sources like radio and television, they argued that being engaged in various household activities deters their access to these sources of information. From this finding, it appears evident that some women in this study had limited exposure to mass media sources. This, as a result, limits their exposure to various family planning messages disseminated through these media.

It is also important to note that, although there is increasing evidence that mobile phones have the potential to improve family planning literacy through family planning text messages $(43,44)$, a greater proportion of this study's participants reported not being aware of such an opportunity. The findings demonstrate further that the few women who were aware of the opportunity and have subscribed to family planning text message services tend to ignore the messages sent to them through their mobile phones. This indicates a missed opportunity by the women since this service could help them receive family planning information at their convenience and, as such, allow them to improve their family planning literacy.

Although male involvement in family planning is essential in increasing the support their partners need in the overall uptake of various recommended family planning methods (45), this study's findings illustrate poor male involvement in matters to do with family planning. In fact, most study participants cited poor involvement of their male partners in family planning as one of the major factors limiting their family 
planning literacy and overall utilization of various recommended modern family planning methods. Numerous other studies $(37,45,46)$ have also reported similar findings. Like in the aforementioned studies, this study's participants associated this problem with their partners' limited awareness of matters related to family planning, fear of side effects of modern family planning methods, and preference to have many children. As such, many men are reported to prevent their female partners from engaging in family planning matters.

Further, the findings of this study show that male partners' preference to have many children in their families has led their female partners to ignore various family planning messages that are disseminated through different channels. As such, women's family planning literacy continues to be low. The findings of this study echo those from previous studies $(1,40)$ that have document the role of men as the sole decision-makers in matters related to family planning. These findings also demonstrate the influence men have on their female partners' overall acceptance of various modern family planning methods. This problem, however, can be explained by the fact that for quite a long time, many family planning programs have been focusing on women only, thus, excluding men in the process (47).

\section{Conclusion}

Adequate family planning literacy among women of childbearing age is essential in their general uptake of various modern family planning methods. Findings of this study demonstrate a multitude of factors that impair women's family planning literacy, thus limiting their overall utilization of modern family planning methods. Several mitigation measures need to be taken on board to improve the general family planning literacy of women of childbearing age and eventually increase their overall uptake of various modern family planning methods. Increasing the general literacy level of women in rural areas is pivotal for them to be able to comprehend various family planning messages from different sources. Efforts to integrate family planning education and information with religious teachings should also be strengthened to eliminate social dilemmas preventing women and their male partners from adopting family planning. Further, improving women and their partners' access to family planning information and encouraging continuous and constant exposure to the same has the potential to reduce misconceptions the couples have on family planning, thus significantly changing their attitudes and increase acceptance of various recommended family planning methods. This study supports several initiatives to provide men with family planning education and information so as to influence them to get involved in family planning matters. Future research is needed to explore the perspectives of men on their overall uptake of various family planning methods.

\section{Declarations}

\section{Ethics approval and consent to participate}

The study received ethical approval from the Tanzania National Institute for Medical Research (NIMR) Institutional Review Board (IRB). Permission to conduct the study was also sought from the local authorities in the four selected regions. The study also obtained informed verbal consent from discussion participants before they participated in the study. Consent for minor (below 18 years) was obtained from their parents/guardians in order for them to participate in the study.

\section{Consent for publication}

All authors gave consent for the publication of the manuscript.

\section{Availability of data and materials}

The authors wished to include the guide as suggested, however, the guide contains some more questions which are yet to be used for different manuscripts. As those manuscripts are underwriting, we deem it inappropriate to upload the guide. However, the datasets used and/or analysed during the current study are available from the corresponding author on reasonable request.

\section{Competing interests}

The authors declare that they have no competing interest.

\section{Funding}

This research was funded by the Consortium for Advanced Research Training in Africa (CARTA).

\section{Authors' contributions}

Both MK and FN have equally contributed in designing the study, developing tools, data analysis, and manuscript writing. All authors (MK FN) have approved the manuscript for submission. 
This research was supported by the Consortium for Advanced Research Training in Africa (CARTA). CARTA is jointly led by the African Population and Health Research Center and the University of the Witwatersrand and funded by the Carnegie Corporation of New York (Grant No-B 8606.R02), Sida (Grant No:54100113), the DELTAS Africa Initiative (Grant No: 107768/Z/15/Z) and Deutscher Akademischer Austauschdienst (DAAD). The DELTAS Africa Initiative is an independent funding scheme of the African Academy of Sciences (AAS)'s Alliance for Accelerating Excellence in Science in Africa (AESA) and supported by the New Partnership for Africa's Development Planning and Coordinating Agency (NEPAD Agency) with funding from the Wellcome Trust (UK) and the UK government. The statements made and views expressed are solely the responsibility of the Fellow".

\section{Authors' information}

Affiliations

\section{Information Studies Programme, University of Dar es Salaam, P. O. Box 35092, Dar es Salaam, Tanzania}

Mohamed Kassim \& Faraja Ndumbaro

\section{References}

1. Anasel MG, Mlinga UJ. Determinants of contraceptive use among married women in Tanzania: Policy implication. African Popul Stud. 2014;28(2):978-88.

2. Starbird E, Norton M, Marcus R. Investing in family planning: key to achieving the Sustainable Development Goals. Glob Heal Sci Pract. 2016;4(2):191-210.

3. Mustafa G, Azmat SK, Hameed W, Ali S, Ishaque M, Hussain W, et al. Family planning knowledge, attitudes, and practices among married men and women in rural areas of Pakistan: findings from a qualitative need assessment study. Int J Reprod Med. 2015;2015.

4. Nansseu JRN, Nchinda EC, Katte J, Nchagnouot FM, Nguetsa GD. Assessing the knowledge, attitude and practice of family planning among women living in the Mbouda health district, Cameroon. Reprod Health [Internet]. 2015;1-7. Available from: http://dx.doi.org/10.1186/s12978-015-0085-9

5. Solanke BL. Drivers of unmet need for family planning among women of advanced reproductive age in urban Western Africa. In: Family Planning. 2018.

6. Mahadeen Al, Khalil AO, Sato T, Imoto A. Knowledge, attitudes and practices towards family planning among women in the rural southern region of Jordan. East Mediterr Health J. 2012;18(6):567-72.

7. United Nations. World Fertility and Family Planning 2020: Highlights. New York: United Nations; 2020. Available from: https://www.un.org/en/development/desa/population/publications/pdf/family/World_Fertility_and_Family_Planning_2020_Highlights.pdf

8. World Health Organization. Family planning / Contraception [Internet]. 2020 [cited 2020 May 13]. p. 1-9. Available from: https://www.who.int/news-room/fact-sheets/detail/family-planning-contraception

9. Tolefac PN, Nana TN, Yeika EV, Awungafac NS, Ntsama Y, Njotang PN. Trends and patterns of family planning methods used among women attending family planning clinic in a rural setting in sub - Sahara Africa: the case of Mbalmayo District Hospital , Cameroon. BMC Res Notes [Internet]. 2018;11(541):10-4. Available from: https://doi.org/10.1186/s13104-018-3658-1

10. Sedgh G, Ashford LS, Hussain R. Unmet need for contraception in developing countries: examining women 's reasons for not using a method. New York; 2016.

11. Afnan-holmes H, Magoma M, John T, Levira F, Msemo G, Armstrong CE, et al. Tanzania's countdown to 2015: an analysis of two decades of progress and gaps for reproductive, maternal, newborn, and child health, to inform priorities for post-2015. Lancet Glob Heal. 2015;3:396-409.

12. Ministry of Health Community Development Gender Elderly and Children. Tanzania National Family Planning Costed Implementation Plan 2019-2023. Dar es Salaam; 2019.

13. MoHCDGEC, MoH, NBS, OCGS, ICF. Tanzania demographic and health survey and malaria indicator survey (THDS-MIS) 2015-16. Dar es Salaam; 2016.

14. UNFPA Tanzania. Fact Sheet: Family Planning. Dar es Salaam; 2018. Available from: https://tanzania.unfpa.org/sites/default/files/pubpdf/familyplanning_A5_13nov_highres.pdf

15. Family Planning 2020. Investing in Family Planning for Tanzania's Health and Development. Dar es Salaam; 2016. Available from: https://www.familyplanning2020.org/resources/investing-family-planning-tanzanias-health-and-development 
16. Shariff H. Family planning in Tanzania: An investment in our women and our future [Internet]. 2020 [cited 2020 Apr 30 ]. p. 1-4. Available from: https://www.devex.com/news/family-planning-in-tanzania-an-investment-in-our-women-and-our-future-84386

17. Chebet JJ, Mcmahon SA, Greenspan JA, Mosha IH, Callaghan-koru JA, Killewo J, et al. "Every method seems to have its problems ": Perspectives on side effects of hormonal contraceptives in Morogoro Region , Tanzania. BMC Womens Health. 2015;15(97):1-12. Available from: http://dx.doi.org/10.1186/s12905-015-0255-5

18. Zureick-Brown S, Newby H, Chou D, Mizoguchi N, Say L, Suzuki E, et al. Understanding global trends in maternal mortality. Int Perspect Sex Reprod Health. 2013;39(1):32-41.

19. Nansseu JRN, Nchinda EC, Katte J, Nchagnouot FM, Nguetsa GD. Assessing the knowledge, attitude and practice of family planning among women living in the Mbouda health district, Cameroon. Reprod Health. 2015;12(92):1-7.

20. Adekannbi JO, Olumide MA. Information literacy of women on family planning in rural communities of Oyo State Nigeria. Inf Dev. 2017;33(4):351-60.

21. Kassim M. Maternal Health Information Needs and Seeking Behaviour of Women in Rural Tanzania: A Case of Mpwapwa District, Dodoma Region. University of Dar es Salaam; 2018.

22. Kilfoyle KA, Conor RO, Bailey SC, Vitko M. Health literacy and women's reproductive health: a systematic review. J Women's Heal. 2016;25(12).

23. Eriksson-Backa K, Ek S, Niemela R, Huotari M-L. Health information literacy in everyday life: A study of Finns aged $65-79$ years. Health Informatics J. 2012;18(2):83-94.

24. Kohan S, Ghasemi S, Dodangeh M. Associations between maternal health literacy and prenatal care and pregnancy outcome. Iran J Nurs Midwifery Res Autumn. 2007;12(4).

25. Ghanbari S, Ramezankhani A, Montazeri A, Mehrabi Y. Health literacy measure for adolescents ( helma ): development and psychometric properties. PLoS One. 2016;11(2zxzr4):1-13.

26. Nutbeam DON. Health literacy as a Public Health Goal: A challenge for contemporary health education and communication strategies into the 21st Century. Health Policy Plan. 2000;15(3):259-68.

27. Vozikis A, Drivas K, Milioris K. Health literacy among university students in greece: determinants and association with self-perceived health , health behaviours and health risks. Arch Public Heal. 2014;72(1):1-6.

28. Shipman J, Kurtz-Rossi S, Funk C. The health information literacy research project. J Med Libr Assoc. 2009;97(4):293-301.

29. Tang C, Wu X, Chen X, Pan B, Yang X. Examining income-related inequality in health literacy and health-information seeking among urban population in China. BMC Public Health. 2019;19(221):1-9.

30. Mprah WK, Anafi P, Yeaboah PYA. Exploring misinformation of family planning practices and methods among deaf people in Ghana Exploring misinformation of family planning practices and. An Int J Sex Reprod Heal Rights. 2017;25(50):20-30.

31. Freer R. Health Literacy and How Rural Communities Understand Hypertension Information in Kabale, Uganda. In: Adult Eduation Research Conference. Kansas: New Prairie Press; 2015.

32. Marimwe C, Dowse R. Health literacy test for limited literacy populations ( HELT-LL ): Validation in South Africa. Cogent Med [Internet]. 2019;6(01). Available from: https://doi.org/10.1080/2331205X.2019.1650417

33. Schrauben SJ, Wiebe DJ. Health literacy assessment in developing countries: a case study in Zambia. Health Promot Int. 2017;32:475-81.

34. Cyril A, Siaity E, Brownie S, Holroyd E. "My husband will love me more if I give birth to more children": rural women's perceptions and beliefs on family planning services utilization in a low resource setting. Int J Africa Nurs Sci [Internet]. 2019;10:152-8. Available from: https://doi.org/10.1016/j.ijans.2019.04.005

35. Hailemariam A, Haddis F. Factors affecting unmet need for family planning in Southern Nations, Nationalities and Peoples Region, Ethiopia. Ethiop J Heal Sci. 2011;21(2):77-89.

36. Safari W, Urassa M, Mtenga B, Changalucha J, Beard J, Church K, et al. Contraceptive use and discontinuation among women in rural North-West Tanzania. Contracept Reprod Med. 2019;4(18):1-10.

37. Ahmed WAM, Shokai BS, Abduelkhair IH, Boshra A. Factors affecting utilization of family planning services in a post-conflict setting , South Sudan: a qualitative study. AIMS Public Heal. 2015;2(4):655-66.

38. Lam Y, Broaddus ET, Surkan PJ. Literacy and healthcare-seeking among women with low educational attainment: analysis of crosssectional data from the 2011 Nepal demographic and health survey. Int J Equity Health. 2013;12(95):1-12.

39. Kim TY, Haider M, Hancock GR, Boudreaux MH. The role of health literacy in family planning use among Senegalese women. J Health Commun. 2019;24(3):244-61.

40. Sundararajan R, Yoder LM, Kihunrwa A, Aristide C, Kalluvya SE, Downs DJ, et al. How gender and religion impact uptake of family planning: results from a qualitative study in Northwestern Tanzania. BMC Womens Health. 2019;19(99):1-10.

Page $11 / 12$ 
41. Kakoko DC, Ketting E, Kamazima SR, Ruben R. Provision of Family Planning Services in Tanzania: A comparative analysis of public and private facilities. Afr J Reprod Health. 2012;16(4):140-8.

42. Kriel Y, Milford C, Cordero J, Suleman F, Beksinska M, Steyn P, et al. Male partner influence on family planning and contraceptive use: perspectives from community members and healthcare providers in KwaZulu-Natal, South Africa. Reprod Health. 2019;16(89):1-15.

43. Lee S, Begley CE, Morgan R, Chan W, Kim S. Addition of mHealth ( mobile health ) for family planning support in Kenya: disparities in access to mobile phones and associations with contraceptive knowledge and use. Int Health. 2019;11:463-71.

44. Mangone ER, Agarwal S, Engle KL, Lasway C, Zan T, Beijma H Van, et al. Sustainable cost models for mHealth at scale: modeling program data from m4RH Tanzania. PLoS One. 2016;1-12.

45. Msovela J, Kessy AT, Mubyazi GM. access to family planning information and contraception methods use among tanzanian men: A CrossSectional Study in Kibaha District. J Epidemiol Prev Med. 2016;1-6.

46. Mselle LT, Kohi TW. Healthcare access and quality of birth care: narratives of women living with obstetric fistula in rural Tanzania. Reprod Health. 2016;13(87):1-9. Available from: http://dx.doi.org/10.1186/s12978-016-0189-x

47. Sensoy N, Korkut Y, Akturan S, Yilmaz M, Tuz C, Tuncel B. Factors affecting the attitudes of women toward family planning. In: Family Planning. Ankara: IntechOpen; 2018. 